In his introductory talk Dr J. E. Field (Cavendish Laboratory) described the laboratory's present high speed camera facilities, which include a 'Fastax', a 'Strobokin', three rotation mirror cameras, capable of microsecond framing rates, and two image converter cameras, the fastest being an 'Imacon' which can give up to twenty pictures at rates up to $10^{7}$ frames a second. These cameras are being used to study many phenomena, including crack propagation, solid and liquid impact, laser irradiation of materials, and the initiation and growth of reaction in explosive materials. The fracture research covers both basic studies and topics of practical interest, such as cleaving of gem stones, the interruption of electric current by fast fracture and fragmentation processes in rock blasting.

Dr M. M. Chaudhri (Cavendish Laboratory) described how he has used high speed microphotography to investigate the detonation of explosives. $\mathrm{He}$ has successfully combined microsecond framing rates with magnification onto the film of approximately 10 times and has studied reaction fronts as they propagate through azide crystals, impact loading of explosives, processes occurring when a needle enters an explosive compact and electrical initiation.

Mr S. N. Heavens (Cavendish Laboratory) has used a continuous access rotating mirror camera (AWRE C4 camera) to study the behaviour of thin layers of solids and liquids when impacted in the drop weight test. This method, which involves dropping a weight, typically $5 \mathrm{~kg}$, onto a thin layer, is used extensively for testing the sensitiveness of explosive materials. The advance here is that $\mathrm{Mr}$ Heavens has successfully photographed the event using transmission photography.

Dr J. J. Camus and Mr D. A. Gorham (Cavendish Laboratory) described their work on high speed liquid impact. Dr Camus has overcome synchronization problems with the Beckman and Whitley 189 camera by explosively driving a plate target against a suspended droplet. In some experiments the droplet has been formed into a two-dimensional disk of liquid, thus allowing the impact and flow processes to be studied in detail. An interesting result is that gases can be trapped between the impacting surfaces and that when these gas pockets subsequently collapse they cause pressure pulses. This is thought to be important in explaining the onset of damage in materials subjected to repeated low velocity liquid impact (as, for example, in steam turbine erosion). Mr Gorham has looked at the impact of high velocity jets (typically $700 \mathrm{~m} \mathrm{~s}^{-1}$ ) on solids using an 'Imacon' camera which allowed him to trigger the camera from the eventa procedure which is impossible with a rotating mirror camera. $\mathrm{He}$ gave several examples to show how high speed drop impact can damage laminate materials.

Three contributions from government laboratories were presented during the conference. Mr D. A. Barnsley (Royal Armament Research and Development Establishment, Fort Halstead, Sevenoaks) reviewed the high speed facilities available at RARDE and $\mathrm{Mr}$ J. F. Gilbert (Atomic Weapons Research Establishment, Foulness) and Mr B. G. Houghton (RARDE, Potton Island) described flash, radiographic facilities available in their respective laboratories. The two machines at AWRE, Foulness, are currently operable at up to $3 \mathrm{MV}$ with a maximum stored energy of $60 \mathrm{~kJ}$ and an output pulse duration of $60 \mathrm{~ns}$. With a target-to-film distance of $2.4 \mathrm{~m}$ reasonable exposure can be achieved after penetration of $\sim 15 \mathrm{~cm}$ in steel. The machine at Potton Island operates at voltages up to $300 \mathrm{kV}$ and gives pulses of duration $100 \mathrm{~ns}$, which are capable of penetrating $\sim 10 \mathrm{~cm}$ of steel.

Both Dr A. W. Palmer (City University) and Dr R. J. Dewhurst (University of Hull) have used 'Imacon' streak

\section{Origin of Archean Schist Relics}

IN this week's Nature Physical Science (April 23), Litherland argues against certain existing and widely accepted models for the origin and evolution of the Archean basement, basing his case on the results of mapping Archean rocks in the Rhodesia Craton. The models in question are those which state or imply that Archean schist (greenstone) belts represent the sites of ancient volcano-sedimentary basins formed, and later deformed, by diapiric behaviour of the underlying primitive crust.

Litherland describes such models as non-uniformitarian in the sense that they take Archean shields to have been formed by the aggregation of separate diapiric granitic nuclei. His own (uniformitarian) conclusion, on the other hand, is that the so-called granitic nuclei are really the end result of a metasomatic process by which schist belts were left as relics of a "folded regional volcanosedimentary succession in a 'sea' of various granitic rocks". It is for this reason that he refers to the four large schist bodies in the investigated northeast corner of Botswana (see map) as schist relics rather than schist belts.

As a result of his geological studies, Litherland concludes, specifically, that the area investigated was first overlain by a sequence of Archean sediments and volcanics, at which stage the supposedly underlying primitive crust was not visible. Following a deformation, which produced the present pattern of steeply dipping beds, there then occurred the emplacement of circular grano-
photography-Dr Palmer to study the breakdown of dielectric liquids and Dr Dewhurst to study ultrashort light pulses from an Nd-glass laser: both events need picosecond time resolution. $\mathrm{Dr}$ Dewhurst has obtained a resolution of 9 ps using an 'Imacon' 600 with an S1 photocathode (an infrared tube).

Examples of the application of cinephotography were given by $\mathrm{Mr} \mathrm{A}$. $\mathbf{R}$. Thompson (University of Sheffield) who has used a camera operating at 3,200 frames a second to study the burning in solid propellent rocket motors. The investigation has yielded valuable information about the factors which affect the stability of the burning. Dr N. Gane and Mr J. A. Williams (Cavendish Laboratory) have used a cinecamera at 32 frames a second to study the metal cutting process. In their experimental arrangement the work piece is moved under the tool in a controlled environment. The resulting film shows clearly how different the metal cutting process is under vacuum conditions, with the occurrence of marked adhesion to the tool and an increase in the thickness of the chip. diorite intrusions and a widespread regional granitization resulting in large and small schist relics floating in tonalite/granodiorite. In other words, the schist relics are mega-xenoliths of the folded volcano-sedimentary succession rather than sites of isolated deposition, and the granodiorite intrusions represent an early phase in the granitic cycle rather than control of sedimentation and deformation by syntectonic diapirs. Subsequently, a second deformation occurred, imposing the dominant tectonic fabric on the area. Litherland's overriding point is thus that the whole suite of rocks can now be seen to have resulted from lateral accretion rather than from isolated deposition between "granitic nuclei" - a uniformitarian, rather than non-uniformitarian, process.

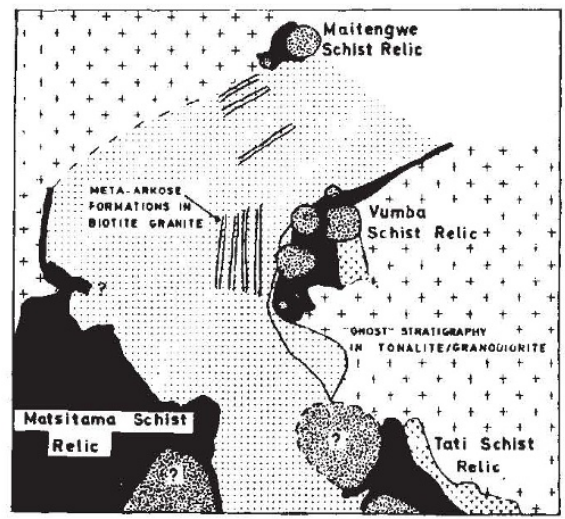

The suggested geological pattern in north-east Botswana before the second deformation, showing the four large schist relics. 